\title{
PENGARUH BUDAYA ORGANISASI DAN LOCUS OF CONTROL TERHADAP KINERJA PEGAWAI CABANG PT. PEGADAIAN (PERSERO) TARANDAM PADANG
}

\author{
Miftahul Hidayat, Aminar Sutra Dewi \\ Sekolah Tinggi Ilmu Ekonomi KBP \\ miftahulhidayat833@gmail.com
}

\begin{abstract}
The purpose of this study to determine how the influence of organizational culture and locus of control on the performance of PT.Pegadaian (Persero) Tarandam Padang. The research method used is descriptive causative. The sampling technique used is the total sampling so that the population is taken as many as 39 respondents. Data analysis technique used is test of validity, reliability, classical assumption test, multiple linear regression test, $F$ test and $t$ test. Based on multiple linear regression analysis, organizational culture variable and locus of control on the performance of PT. Pegadaian (Persero) Tarandam Padang obtained $\mathrm{Y}=13,260+0,896 \mathrm{X}_{1}+0,428 \mathrm{X}_{2}+$ 0,05 . From the result of $t$ test, it is found that organizational culture variables have significant effect on employee performance with significant value $0.000<0,05$, so Ho is rejected and $\mathrm{HI}$ accepted, while locus of control variable has no significant effect to PT. Pawnshop (Persero) Tarandam Padang because significant value $0,037<0.05$, so Ho accepted and $\mathrm{H} 2$ rejected. From result of $F$ test proved that organizational culture variable and locus of control simultaneously have significant influence to PT. Pegadaian (Persero) Tarandam Padang performance with significant value $0,000<0,05$. While Adjusted $R$ Square result is 0,368 , it means free variable influence to variable $36,8 \%$ the rest $63,2 \%$ is explained by other variable not used in this research.
\end{abstract}

Keywords: Organizational Culture, Locus Of Control, and Employee Performance.

\section{PENDAHULUAN}

PT. Pegadaian merupakan perusahaan umum yang berstatus Badan Usaha Milik Negara (BUMN) yang bergerak dibidang pegadaian. Sebagai salah satu badan usaha milik Negara, seharusnya PT. Pegadaian bisa memberikan pelayanan yang baik kepada masyarakat. Oleh karena itu untuk dapat melaksanakan pelayanan yang lebih baik, para pegawai yang ada di Perum Pegadaian dituntut untuk dapat menerapkan langkah-langkah yang mendorong peningkatan kinerja pegawai. Berdasarkan pengamatan yang penulis lakukan, diduga tingkat kinerja Pegawai PT. Pegadaian (Persero) Tarandam Padang masih rendah, hal ini dapat dilihat dari menurun data pelanggan yang menggunakan jasa pegadaian.

Kinerja pegawai PT. Pegadaian dapat dilihat berdasar pengamatan awal atau observasi yang dilakukan masih belum maksimal dalam memberikan pelayanan terhadap masyarakat yang menggunakan jasa pegadaian seperti tidak maksimalnya melayani pelanggan dalam hal peminjaman dana dimana pegawai perum lambat dalam melansir jaminan untuk memberi pinjaman penebusan jaminan memakai waktu yang lama seperti ketika pelunas pinjaman di pagi dalam tebusan tidak dapat di ambil pada saat itu juga bisa 
di ambil siang hari atau besok hari karena kunci brangkas di pegang satu pegawai saja jaminan ditukar terlalu rendah, pegawai yang melayani tidak cekatan.

Permasalahan yang dihadapi oleh Pegawai PT. Pegadaian (Persero) Tarandam Padang dalam hubungannya dengan Locus of control yaitu pegawai cenderung kurang mampu untuk mengatasi penurunan kinerjanya. hal ini disebabkan oleh kecenderungan pegawai yang kurang aktif, pegawai lebih menyenangi perintah dari atasan, pegawai kurang berusaha untuk menyelesaikan pekerjaan dengan segera sehingga kinerjanya tidak berorientasi pada produktivitas tugas. Falikhatun dalam Abdullah (2006:19) menyatakan bahwa kinerja juga dipengaruhi oleh tipe personalitas individu, yaitu individu dengan Internal Locus of control lebih banyak berorientasi pada tugas yang dihadapinya, sehingga akan meningkatkan kinerjanya. Penurunan Kinerja pegawai dapat menimbulkan perasaan yang tidak nyaman bagi pegawai, sehingga menyebabkan ketidakberdayaan dan kekhawatiran. Selain itu adanya sikap kurang percaya diri terhadap kemampuannya sendiri terkadang berdampak negatif pada kinerjanya. Kegagalan kerja karyawan dipandang oleh sebagian karyawan sebagai penilaian dari pimpinan, di sisi lain keberhasilan pegawai dipandang sebagai hasil dari sendiri (Falikhatun,dalam Abdullah:20).

Kinerja pegawai PT. Pegadaian (Persero) Tarandam Padang perlu diperhatikan oleh pihak manajemen karena kinerja tersebut berhubungan langsung dengan pelayanan kepada masyarakat, sehingga apabila pelayanannya baik maka masyarakat atau nasabah akan merasa puas dengan kinerja cabang PT. Pegadaian (Persero) Tarandam Padang.

Perumusan Masalah

Berdasarkan uraian diatas, maka perumusan masalah dalam penelitian ini adalah sebagai berikut:

1. Bagaimana pengaruh budaya Organisasi terhadap kinerja PT.Pegadaian (Persero) Tarandam Padang.

2. Bagaimana pengaruh locus of control terhadap kinerja PT.Pegadaian (Persero) Tarandam Padang.

\section{LANDASAN TEORI \\ Kinerja}

Menurut Hamali (2016:98), kinerja merupakan hasil pekerjaan yang mempunyai hubungan kuat dengan tujuan strategis organisasi, kepuasan konsumen dan memberikan kontribusi pada ekonomi. Kinerja adalah tentang melakukan pekerjaan dan hasil yang dicapai dari pekerjaan tersebut. Menurut pendapat Mangkunegara (2001:75) indikator dari kinerja antara lain, yaitu:

1. Kualitas kerja, terdiri dari ketepatan, ketelitian dan kebersihan

2. Kuantitas kerja, kuantitas kerja yang diperhatikan instruksi, hati-hati, kerajinan, output rutin dan output kerajinan ekstra dan juga seberapa cepat penyelesaian kerja ekstra.

3. Dapat tidaknya diandalkan, merupakan kemampuan karyawan dalam memecahkan masalah, penguasan terhadap kerja, dan tanggung jawab terhadap kekerjaan

4. Sikap, yang diperhatikan adalah sikap terhadap pimpinan, pegawai lain dan lingkungan kerja.

\section{Budaya organisasi}

Menurut Peter dan Watermen (2006:41), Budaya organisasi sebagai suatu pola dari asumsi-asumsi dasar yang ditemukan, diciptakan, atau dikembangkan oleh suatu kelompok tertentu dengan maksud agar organisasi belajar mengatasi atau menanggulangi masalah-masalah yang timbul akibat adaptasi eksternal dan integrasi internal yang sudah berjalan dengan cukup baik, sehingga, perlu diajarkan kepada anggota-anggota baru 
sebagai cara yang benar untuk memahami, memikirkan dan merasakan berkenaan dengan masalah-masalah tersebut. Menurut Robbins (2008:289) dikemukakan karakteristik primer yang kesemuanya menjadi elemen penting dari suatu budaya organisasi, yang selanjutnya dijadikan indicator untuk mengukur budaya organisasi dalam penelitian ini, yaitu:

1. Memperhatikan kerincian, sejauhmana para karyawan diharapkan memperlihatkan presisi (kecermatan), analisis, dan perhatian kepada rincian.

2. Orientasi hasil, sejauh mana manajemen memfokuskan pada hasil bukannya pada teknik dan proses yang digunakan untuk mencapai hasil itu.

3. Orientasi orang, sejauh mana keputusan manajemen memperhitungkan efek hasilhasil pada orang-orang didalam organisasi itu.

4. Orientasi tim, sejauh mana kegiatan kerja diorganisasikan disekitar tim-tim, bukannya individu-individu

5. Keagresifan, sejauh mana orang-orang itu agresif dan kompetitif bukannya santaisantai.

6. Kemantapan, sejauh mana kegiatan organisasi menekankan dipertanyakannya status quo sebagai kontras dari pertumbuhan.

\section{Locus of control}

Menurut Forte (2008:23), locus of control mengacu pada kondisi-kondisi dimana individu mengatribusikan kesuksesan dan kegagalan mereka. Indikator Locus of control Menurut Crider (2010:17)adalah sebagai berikut:

a. Segala yang dicapai individu hasil dari usaha sendiri.

b. Menjadi pimpinan karena kemampuan sendiri.

c. Keberhasilan individu karena kerja keras.

d. Segala yang diperoleh individu bukan karena keberuntungan.

e. Kemampuan individu dalam menentukan kejadian dalam hidup.

f. Kehidupan individu ditentukan oleh tindakannya 


\section{METODE PENELITIAN}

\section{Populasi dan Sampel}

Penelitian yang akan penulis lakukan, populasinya adalah semua pegawai yang bekerja di PT. Pegadaian (Persero)Tarandam Padang yang berjumlah 39 orang. Teknik pengambilan sampel dalam penelitian ini adalah teknik total sampling, dimana seluruh populasi yang ada menjadi sampel penelitian. Arikunto (2002:103) mengemukakan jika jumlah populasi kurang dari 100 orang maka penentuan jumlah sampel ditentukan secara total sampling. Jumlah sampel dalam penelitian ini adalah 39 orang.

\section{Teknik Analisis Data}

Setelah data-data terkumpul selanjutnya dilakukan analisis data sebagai berikut :

\section{Uji validitas}

Uji validitas digunakan untuk mengukur sah atau valid tidaknya suatu kuesioner. Penguji validitas tiap butir digunakan analisa item, yaitu mengkorelasikan skor tiap butir dengan skor total yang merupakan jumlah tiap butir (corrected item total correlation). Validnya sebuah ditentukan dari nilai koefisien kolerasi yang dihasilkan besar dari 0,30 dan dapat digunakan untuk selanjutnya (Sugiono 2005).

\section{Uji Reliabilitas}

Menurut Ghozali (2007:45), reliabilitas sebenarnya adalah alat untuk mengukur suatu kuesioner yang merupakan indikator dari suatu variabel atau konstruk, untuk menilai kehandalan dari item-item pertanyaan yang valid yang dilihat dari nilai cronbach alpha yang dihasilkan > 0,60 (Sugiono, 2005).

\section{Analisis Deskriptif}

Analisis ini bermaksud untuk menggambarkan karakteristik masing-masing variabel penelitian.

\section{Asumsi Klasik}

Uji asumsi klasik juga tidak perlu dilakukan untuk analisis regresi linear yang bertujuan untuk menghitung nilai pada variable tertentu.

\section{a. Uji Normalitas}

Menurut Ghozali (2011) uji normalitas adalah uji yang digunakan untuk melihat apakah dalam regresi, variabel dependen dan variabel independen atau keduanya mempunyai distribusi normal atau tidak dengan nilai asymp signifikan > alpha 0,05. Namun jika nilai asymp signifikan > alpha 0,05 dikatakan terdistribusi tidak normal.

\section{b. Uji Heteroskedastisitas}

Menurut Ghozali (2008), uji heteroskedastisitas bertujuan untuk menguji apakah dalam model regresi terjadi ketidaksamaan varians dari residual satu pengamatan ke pengamatan yang lain. Dalam uji ini apabila bila signifikansi $>0,05$ atau kesalahan menolak data maka tidak terdapat gejala heteroskedastisitas, model yang baik adalah tidak terjadi heteroskedastisitas (Ghozali, 2005).

\section{c. Uji Multikolonieritas}

Menurut Ghozali (2008), untuk mendeteksi ada atau tidaknya multikolinearitas dapat dilihat dari nilai Tolerance dan Variance Inflation Factor (VIF). Nilai tolerance yang umum dipakai adalah $>0,10$ atau sama dengan nilai VIF $<10$ yang menandakan tidak terjadinya multikolinearitas.

\section{Analisi Regresi Linear Berganda}

Regresi Linear Berganda merupakan salah satu teknik analisis data yang sering digunakan oleh seorang peneliti yang menggunakan pendekatan penelitian kuantitatif. Regresi Linear Berganda dinotasi kandalam persamaan berikut ini:

$\mathrm{Y}=\mathrm{a}+\mathrm{b}_{1} \mathrm{X}_{1}+\mathrm{b}_{2} \mathrm{X}_{2}+\mathrm{e}$ 
Keterangan:

$\mathrm{Y}=$ Kinerja

$\mathrm{a}=$ Konstanta

$\mathrm{X}_{1}$ = Budaya organisasi

$\mathrm{X}_{2}=$ Locus of control

$\mathrm{b}_{1} \quad$ Koefisien regresi Budaya organisasi

$\mathrm{b}_{2} \quad=$ Koefisien regresi Locus of control

e $=$ Standar error

\section{Uji F}

Uji $\mathrm{F}$ digunakan untuk mengetahui pengaruh semua variable bebas secara bersamasama terhadap nilai variable terikat. Pengujian ini akan dilakukan dengan menguji $\mathrm{F}$ pada tingkat kepercayaan 95\% $(\mathrm{a}=0,05)$ dan derajat kebebasan tertentu, sehingga dengan penguji uji $\mathrm{F}$ ini akan diketahui hubungan variabel independent $(\mathrm{X})$ dengan variabel dependent (Y).

\section{Uji t}

Koeefisien regresi bertujuan untuk mengetahui apakah variabel bebas yang terhadap dalam persamaan secara individu berpengaruhterhadap nilai variabel terikat. Caranya adalah dengan melakukan pengujian hipotesis terhadap koefisien regresi semua dari hasil hipotesis ini, pada tingkat kepercayaan dan derajat kebebasan tertentu akan diperoleh hasil $\mathrm{t}$ hitung dan $\mathrm{t}$ tabel, sehingga dapat disimpulkan pengaruh antara variabel independent dengan dependent.

\section{Uji $\mathbf{R}^{2}$}

Yaitu digunakan untuk mengetahui prosentase pengaruh semua variabel bebas terhadap nilai variabel terikat. Besarnya koefisien determinasi dari 0 sampai dengan 1, semakin mendekati 0 besarnya koefisien determinasi suatu persamaan regresi, maka semakin kecil pengaruh semua variabel bebas terhadap nilai variabel terikat. Sebaiknya, semakin mendekati 1 besarnya koefisuen determinasi suatu persamaan regresi, maka semakin besar pula pengaruh semua variabel bebas terhadap variabel terikat.

\section{HASIL PENELITIAN}

\section{Hasil Uji Instrumen}

Hasil Uji Validitas

Variabel budaya organisasi yang terdiri dari 15 (lima belas) butir pernyataan memiliki nilai corrected item-total correlation antara 0,338-0,680 atau dengan kata lain bahwa 15 (lima belas) butir pernyataan yang digunakan dalam mengukur variabel budaya kerja dinyatakan valid karena nilai corrected item-total correlation lebih besar dari nilai $\mathrm{r}_{\text {-tabel }}$ yaitu sebesar 0,30 .

Variabel locus of control yang terdiri dari 16 (enam belas) butir pernyataan memiliki nilai corrected item-total correlation antara 0,305-0,633 atau dengan kata lain bahwa 16 (enam belas) butir pernyataan yang digunakan dalam mengukur variabel locus of control dinyatakan valid karena nilai corrected item-total correlation lebih besar dari nilai $\mathrm{r}_{\text {-tabel }}$ yaitu sebesar 0,30 .

Variabel kinerja karywan yang terdiri dari 23 (dua puluh tiga) butir pernyataan memiliki nilai corrected item-total correlation antara 0,379-0,680 atau dengan kata lain bahwa 23 (dua puluh tiga) butir pernyataan yang digunakan dalam mengukur variabel kinerja karyawan dinyatakan valid karena nilai corrected item-total correlation lebih besar dari nilai $r_{-}$tabel yaitu sebesar 0,30.

\section{Hasil Uji Reliabilitas}


Uji reliabilitas yang dihasilkan nilai Cronbach's Alpha untuk variabel budaya organisasi, locus of control dan kinerja karyawan dinyatakan reliabel karena nilai Cronbach's Alpha yang dihasilkan lebih dari 0,60 sehingga item-item pernyataan termasuk dalam kategori handal dan variabel tersebut dapat digunakan sebagai alat ukur dalam penelitian ini.

\section{Hasil Uji Deskriptif}

\section{Deskriptif Variabel Budaya Organisasi $\left(\mathbf{X}_{1}\right)$}

Berdasarkan pengujian dapat diketahui bahwa sebagian besar responden memberikan penilaian terhadap variabel budaya organisasi untuk menentukan kinerja karyawan PT. Pegadaian (Persero) Tarandam Padang terlihat pada penilaian tertinggi terdapat pada pernyataan No. 5, yaitu saya mampu melaksanakan standar kerja yang ditentukan perusahaan dengan nilai TCR sebesar 78\% dengan kategori baik.

Selanjutnya penilaian terendah pada variabel budaya organisasi terdapat pada pernyataan No. 9, yaitu saya merasa senang dengan pekerjaan yang saya tekuni karena dapat memberikan manfaat bagi organisasi yang memotivasi saya dalam bekerja dengan nilai TCR sebesar 64,2\% dengan kategori baik.

\section{Deskriptif Variabel Locus Of Control $\left(\mathrm{X}_{2}\right)$}

Berdasarkan pengujian dapat diketahui bahwa sebagian besar responden memberikan penilaian terhadap variabel locus of control untuk menentukan kinerja karyawan PT. Pegadaian (Persero) Tarandam Padang terlihat pada penilaian tertinggi terdapat pada pernyataan No. 2, yaitu pada kebanyakan pekerjaan, saya dapat dengan mudah menyelesaikan apapun yang telah saya tetapkan untuk diselesaikan dengan nilai TCR sebesar $85,4 \%$ dengan kategori baik.

Selanjutnya penilaian terendah pada variabel locus of control terdapat pada pernyataan No. 10, yaitu ketika akan memperoleh pekerjaan yang sangat bagus orang - orang yang saya kenal lebih penting dari pada keahlian dan kemampuan yang saya miliki dengan nilai TCR sebesar $65,2 \%$ dengan kategori baik.

\section{Deskriptif Variabel Kinerja Karyawan (Y)}

Berdasarkan pengujian dapat diketahui bahwa sebagian besar responden memberikan penilaian terhadap variabel kinerja karyawan karyawan PT. Pegadaian (Persero) Tarandam Padang terlihat pada penilaian tertinggi terdapat pada pernyataan No. 7, yaitu dalam melaksanakan tugas saya selalu bekerja dan berbuat secara efisien. dengan nilai TCR sebesar 77,4\% dengan kategori baik.

Selanjutnya penyebab terendah pada variabel kinerja karyawan PT. Pegadaian (Persero) Tarandam Padang terdapat pada No. 8, yaitu saya melaksanakan tugas dan tanggung jawab yang dibebankan kepada saya dengan nilai TCR sebesar 63\% dan pada pernyataan No. 19 saya merapikan kembali peralatan pekerjaan yang saya pergunakan dalam melaksanakan pekerjaan dengan nilai TCR sebesar 63\%, dengan kategori baik.

\section{Uji Asumsi Klasik}

\section{Uji Normalitas}

Berdasarkan pada pengujian hasil uji normalitas yang dilakukan di atas budaya organisasi, locus of control dan kinerja karyawan terlihat bahwa data yang ada telah terdistribusi dengan normal karena nilai signifikan ketiga variabel lebih besar dari 0,05.

\section{Uji Heteroskedastisitas}

Berdasarkan pada pengujian dapat diketahui bahwa nilai signifikan budaya kerja sebesar 0,939 dan variabel locus of control memiliki nilai signifikan 0,159, hal ini berarti kedua variabel tersebut tidak terdapat gejala heterokesdatisitas karena nilai signifikan yang dihasilkan $>0,05$.

\section{Uji Multikolonieritas}


Berdasarkan pengujian di atas dapat diketahui bahwa tolerance value untuk masing-masing variabel lebih kecil dari 10 sedangkan nilai Variance Inflation Factor (VIF) untuk masing-masing variabel lebih kecil dari 10. Dengan demikian dapat disimpulkan model yang digunakan dalam penelitian ini tidak mengandung gangguan multikolinieritas.

\section{Uji Regresi Linear Berganda}

Tabel. 1

Hasil Uji Regresi Linear Berganda

Coefficients $^{\mathrm{a}}$

\begin{tabular}{|c|c|c|c|c|c|}
\hline \multirow[b]{2}{*}{ Model } & \multicolumn{2}{|c|}{$\begin{array}{l}\text { Unstandardized } \\
\text { Coefficients }\end{array}$} & \multirow{2}{*}{$\begin{array}{c}\begin{array}{c}\text { Standardized } \\
\text { Coefficients }\end{array} \\
\text { Beta }\end{array}$} & \multirow[b]{2}{*}{$\mathrm{T}$} & \multirow[b]{2}{*}{ Sig. } \\
\hline & B & Std. Error & & & \\
\hline $1 \quad$ (Constant) & 13,260 & 15,677 & & 0,846 & 0,403 \\
\hline Budaya_Organisasi & 0,896 & 0,206 & 0,562 & 4,353 & 0,000 \\
\hline Locus_Of_Control & 0,428 & 0,198 & 0,279 & 2,165 & 0,037 \\
\hline
\end{tabular}

a. Dependent Variable: Kinerja_Karyawan

Sumber: Data primer yang diolah, 2017

Berdasarkan analisis data dengan menggunakan program SPSS 20 for windows, maka diperoleh hasil persamaan regresi sebagai berikut:

$\mathrm{Y}=13,260+0,896 \mathrm{X}_{1}+0,428 \mathrm{X}_{2}+0,05$

1) Nilai constanta adalah $=13,260$ artinya jika tidak terjadi perubahan variabel budaya organisasi dan locus of control (nilai $\mathrm{X}_{1}$ dan $\mathrm{X}_{2}$ adalah 0) maka kinerja karyawan pada PT. Pegadaian (Persero) Tarandam Padang tetap sebesar 13,260 satuan.

2) Nilai koefisien regresi budaya organisasi adalah $=0,896$ artinya jika variabel budaya organisasi $\left(\mathrm{X}_{1}\right)$ meningkat sebesar 1 (satuan) dengan asumsi variabel locus of control $\left(\mathrm{X}_{2}\right)$ dan konstanta (a) adalah 0 (nol), maka kinerja karyawan PT. Pegadaian (Persero) Tarandam Padang meningkat sebesar 0,896 satuan.

3) Nilai koefisien regresi locus of control adalah $=0,428$ artinya jika variabel locus of control $\left(\mathrm{X}_{2}\right)$ meningkat sebesar 1 (satuan) dengan asumsi variabel budaya organisasi $\left(\mathrm{X}_{1}\right)$ dan konstanta (a) adalah 0 (nol), maka kinerja karyawan PT. Pegadaian (Persero) Tarandam Padang meningkat sebesar 0,428 satuan.

\section{Uji Hipotesis}

Uji F

Uji F digunakan untuk mengetahui pengaruh semua variabel bebas secara bersamasama terhadap nilai variabel terikat. Berdasarkan uji $\mathrm{F}$ yang dilakukan dapat dilihat pada Tabel di bawah ini:

\section{Tabel 2}

\section{Hasil Uji F}

ANOVA $^{\mathrm{b}}$

\begin{tabular}{|c|c|c|c|c|c|c|}
\hline \multicolumn{2}{|c|}{ Model } & Sum of Squares & Df & $\begin{array}{l}\text { Mean } \\
\text { Square }\end{array}$ & $\mathrm{F}$ & Sig. \\
\hline \multirow[t]{3}{*}{1} & Regression & 1754,281 & 2 & 877,141 & 12,041 & $0,000^{b}$ \\
\hline & Residual & 2622,386 & 36 & 72,844 & & \\
\hline & Total & 4376,667 & 38 & & & \\
\hline
\end{tabular}

a. Predictors: (Constant), Locus_Of_Control, Budaya_Organisasi

b. Dependent Variable: Kinerja_Karyawan

Berdasarkan hasil pengujian pada Tabel di atas dapat dilihat pada nilai $\mathrm{F}_{\text {hitung }}$ sebesar 9,169 dengan nilai $\mathrm{F}_{\text {tabel }} d f_{2}=\mathrm{k}-1 \quad(3-1=2), d f_{1}=\mathrm{n}-\mathrm{k}(39-3=36)$ adalah 3.26 sehingga nilai $\mathrm{F}_{\text {hitung }} 12,041>\mathrm{F}_{\text {tabel }} 3,26$, dan tingkat signifikan $0,000<0,05$ maka Ho ditolak dan $\mathrm{H}_{3}$ diterima, dapat disimpulkan bahwa variabel budaya organisasi dan locus of control 
$\left(\mathrm{X}_{2}\right)$ secara bersamaan berpengaruh signifikan terhadap kinerja karyawan PT. Pegadaian (Persero) Tarandam Padang.

Uji t

Koeefisien regresi bertujuan untuk mengetahui apakah variabel bebas yang terhadap dalam persamaan secara individu berpengaruhterhadap nilai variabel terikat. Berdasarkan uji t yang dilakukan dapat dilihat pada Tabel 3 di bawah ini:

\section{Tabel 3}

\section{Hasil Uji t}

Coefficients $^{\mathrm{a}}$

\begin{tabular}{|c|c|c|c|c|c|}
\hline \multirow[b]{2}{*}{ Model } & \multicolumn{2}{|c|}{ Unstandardized Coefficients } & \multirow{2}{*}{$\frac{\begin{array}{c}\text { Standardized } \\
\text { Coefficients }\end{array}}{\text { Beta }}$} & \multirow[b]{2}{*}{$\mathrm{T}$} & \multirow[b]{2}{*}{ Sig. } \\
\hline & $\mathrm{B}$ & Std. Error & & & \\
\hline 1 (Constant) & 13,260 & 15,677 & & 0,846 & 0,403 \\
\hline Budaya_Organisasi & 0,896 & 0,206 & 0,562 & 4,353 & 0,000 \\
\hline Locus_Of_Control & 0,428 & 0,198 & 0,279 & 2,165 & 0,037 \\
\hline
\end{tabular}

a. Dependent Variable: Kinerja_Karyawan

Sumber : Data primer yang diolah, 2017

Berdasarkan hasil yang yang dilakukan pada tabel 3 dapat diketahui bahwa apabila nilai $t_{\text {hitung }}>t_{\text {tabel }}$ dan nilai signifikan $<0,05$, maka dapat dikatakan bahwa variabel bebas tersebut berpengaruh signifikan secara individu terhadap variabel terikat.

\section{Uji Koefisien Determinasi}

Besarnya koefisien determinasi dari 0 sampai dengan 1, semakin mendekati 0 besarnya koefisien determinasi suatu persamaan regresi, maka semakin kecil pengaruh semua variabel bebas terhadap nilai variabel terikat. Berdasarkan uji koefisien determinasi yang dilakukan maka dapat dilihat pada Tabel 4 berikut ini:

\section{Tabel 4}

\section{Hasil Uji Koefisien Determinasi}

Model Summary

\begin{tabular}{|c|c|c|c|c|c|c|c|c|c|}
\hline \multirow[b]{2}{*}{ Model } & \multirow[b]{2}{*}{ R } & \multirow[b]{2}{*}{ R Square } & \multirow[b]{2}{*}{$\begin{array}{c}\text { Adjusted R } \\
\text { Square }\end{array}$} & \multirow[b]{2}{*}{$\begin{array}{l}\text { Std. Error of } \\
\text { the Estimate }\end{array}$} & \multicolumn{5}{|c|}{ Change Statistics } \\
\hline & & & & & $\begin{array}{c}\text { R Square } \\
\text { Change }\end{array}$ & F Change & df1 & df2 & $\begin{array}{l}\text { Sig. F } \\
\text { Change }\end{array}$ \\
\hline 1 & $0,633^{\mathrm{a}}$ & 0,401 & 0,368 & 8,535 & 0,401 & 12,041 & 2 & 36 & 0,000 \\
\hline
\end{tabular}

a. Predictors: (Constant), Locus_Of_Control, Budaya_Organisasi

Sumber: Data primer yang diolah, 2017

Berdasarkan Tabel 4 dapat diketahui bahwa nilai koefisien determinasi terdapat pada nilai Adjusted $R$ Square dengan sebesar 0,368. Hal ini berarti besar pengaruh variabel bebas terhadap variabel terikat adalah sebesar 36,8\% sisanya $63,2 \%$ dijelaskan oleh variabel lain ya ng tidak dibahas dalam penelitian ini.

\section{Pembahasan Hasil Penelitian}

\section{1) Pengaruh Variabel Budaya Organisasi Terhadap Kinerja Karyawan.}

Berdasarkan penelitian yang telah dilakukan pada variabel budaya kerja ditemukan nilai $t_{\text {hitung }}>\mathrm{t}_{\text {tabel }}(4,353>1,688)$, sedangkan nilai signifikan 0,000 , artinya terdapat pengaruh yang signifikan antara variabel budaya kerja dengan kinerja karyawan. Berdasarkan hasil penelitian tersebut dapat disimpulkan bahwa kinerja karyawan PT. Pegadaian (Persero) Tarandam Padang disebabkan oleh beberapa faktor seperti perhatian kerincian, orientasi hasil, orientasi orang, orientasi tim dan keagresifan. Sehingga karyawan dapat melaksanakan tanggung jawab yang diberikan kepadanya dengan baik baik, serta karyawan merasa senang dengan pekerjaan yang diberikan kepadanya karena pekerjaan tersebut telah sesuai dengan kemampuan yang dimiliki. Dengan adanya 
kemampuan yang dimiliki karyawan terhadap pekerjaan tersebut maka karyawan dapat bekerja dengan baik sehingga dapat membantu dalam pencapaian tujuan organisasi.

Penelitian relevan atau sama dengan penelitian Yanto (2014) yang berjudul pengaruh budaya organisasi dan komitmen organisasi terhadap kinerja karyawan PT. Pegadaian (Persero) Cabang tarandam padang. Dari hasil penelitian tersebut ditemukan bahwa terdapat pengaruh positif antara budaya organisasi terhadap kinerja karyawan PT.Pegadaian (Persero) Cabang.

\section{2) Pengaruh Variabel Locus Of Control Terhadap Kinerja Karyawan.}

Berdasarkan hasil penelitian yang dilakukan pada variabel locus of control ditemukan nilai $\mathrm{t}_{\text {hitung }}>\mathrm{t}_{\text {tabel }}(2,165>1,688)$ sedangkan nilai signifikan 0,037 . Artinya variabel locus of control berpengaruh terhadap kinerja karyawam. Berdasarkan hasil tersebut dapat disimpulkan bahwa kinerja karyawan PT. Pegadaian (Persero) Tarandam Padang dapat dipengaruhi oleh faktor internal locos of Control dan external locus of Control. Hal ini disebabkan karena promosi jabatan yang diberikan kepada karyawan telah sesuai dengan ketentuan yang berlaku, sehingga promosi jabatan yang terjadi pada karyawan merupakan salah satu keberuntungan, bukan berdasarkan prestasi kerja karyawan, tetapi berdasarkan pendekatan antara pimpinan. Dengan terjadinya pemasalahan tersebut maka nantinya akan memberikan dampak yang positif terhadap kinerja karyawan, karena karyawan termotivasi untuk bekerja lebih baik lagi. Dalam rangka meningkatkan kinerja karyawan seharusnya pimpinan memberikan promosi jabatan berdasarkan prestasi kerja pada karyawan agar karyawan tersebut memiliki semangat yang tinggi untuk bekerja ke arah yang lebih baik.

Penelitian ini sama dengan penelitian yang dilakukan oleh Abdulloh (2006) yang berjudul pengaruh budaya organisasi, locus of control dan kepuasan kerja terhadap kinerja karyawan pada kantor pelayanan pajak semarang barat. Berdasarkan penelitian tersebut didapatkan bahwa terdapat pengaruh positif dan signifikan antara locus of control terhadap kinerja karyawan.

\section{SIMPULAN} berikut:

Berdasarkan penelitian yang telah dilakukan, maka dapat ditarik kesimpulan sebagai

1. Variabel budaya organisasi berpengaruh secara positif dan signifikan terhadap kinerja karyawan PT. Pegadaian (Persero) Tarandam Padang dengan tingkat capaian responden sebesar $70,35 \%$ dengan baik.

2. Variabel locus of control berpengaruh secara positif dan signifikan terhadap kinerja karyawan PT. Pegadaian (Persero) Tarandam Padang dengan tingkat capaian responden sebesar $79 \%$ dengan kriteria baik

\section{DAFTAR PUSTAKA}

Afriani, R., \& Susanti, F. (2018). Pengaruh Emotional Intelligence Terhadap Academic Achievement: Locus Of Control Sebagai Mediator (Studi Pada Siswa SMA N 9 Padang). https://doi.org/10.31227/osf.io/6yhu4

Ayu, D. G., \& Mayliza, R. (2019). Pengaruh Budaya Organisasi, Kompensasi Non Finansial, Dan Job Insecurity Terhadap Turnover Intention Pada PT. BPR Cincin Permata Andalas Cabang Padang. https://doi.org/10.31219/osf.io/nd8ta

Forte, A. 2008. Locus of Control and The Moral Reasoning of Managers. Pustaka Pesantren. Yogyakarta. 
Ghozali, Imam. 2007. Aplikai Analisis Multivarite dengan SPSS, Semarang: Cetakan Keempat, Badan Penerbit Universitas Diponegoro.

Hamali, Arif, Yusuf, 2016, Pemahaman Manajemen Manajemen Sumber Daya Manusia. Cetak Pertama, Yogyakarta: Buku Seru.

Hasibuan, M. 2001. Organisasi dan Motivasi: Dasar Peningkatan Produktivitas.Jakarta: Bumi Aksara

Gomes. 2003. Manajemen Sumber Daya Manusia. Yogyakarta: Gadjah Mada University Press.

Grimes, PW. 2007. Evaluation of Teaching and Locus of Control. Pearson. Prentice Hall. New York.

Junaidi, R., \& Susanti, F. (2019). Pengaruh Gaya Kepemimpinan Dan Budaya Organisasi Terhadap Kinerja Pegawai Pada UPTD Baltekkomdik Dinas Pendidikan Provinsi Sumatera Barat. https://doi.org/10.31227/osf.io/bzq75

Larsen, Randy J \& David M. Buss. 2010. Personality Psychology: Domain of Knowledge About Human Nature.: Mc Graw Hill Companies. America, Newyork.

Mangkunegara, Anwar, Prabu. 2001. Manajemen Sumber Daya Manusia. Perusahaan, Bandung: Remaja Rosda Karya.

Mangkunegara, Anwar, Prabu. 2013. Manajemen Sumber Daya Manusia Perusahaan. Bandung: Remaja Rosdakarya.

Peter dan Watermen. 2006. Pengukuran Kinerja Berbasis Kompetensi. Jakarta: PT. Raja Grafindo Persada.

Rivai, Veithzal. 2005. Manajemen Sumber Daya Manusia Untuk Perusahaan. Edisi Pertama. Jakarta: PT Raja Grafindo Persada.

Robbins, Judge.2008. Perilaku Organisasi : Konsep, Kontroversi, Aplikasi. Edisi Bahasa Indonesia. Jakarta: PT.Prenhallindo.

Sugiyono. 2005. Metode Penelitian Pendidikan Kuantitatif, Kualitatif dan R\&D. CV. Alfabeta. Bandung.

Sutrisno, Edy, 2015, Manjemen Sumber Daya Manusia, Edisi pertama. Cetakan ke tujuh, Jakarta: Kencana Prenadamedia Group. 